\title{
ANALISIS PERAN KEPALA SEKOLAH DALAM MENGEMBANGKAN MUTU PENDIDIKAN DI SD NEGERI O01 BONAI DARUSSALAM KABUPATEN ROKAN HULU
}

\author{
Lulu Lestari ${ }^{1}$, Elpri Darta Putra ${ }^{1}$ \\ ${ }^{1}$ Universitas Islam Riau, Indonesia \\ *Corresponding email: lululestari705@gmail.com
}

Naskah diterima: 28 Juni 2021| Disetujui: 4 Agustus2021 | Diterbitkan: 16 Agustus 2021

\begin{abstract}
This study aims to describe the role of the principal in developing the quality of education, the supporting factors in developing the quality of education and the inhibiting factors in developing the quality of education at SD Negeri 001 Bonai Darussalam. This study uses a descriptive qualitative approach. The data sources of this research are the principal and 2 teachers. Data collection techniques and instruments in this case the researchers used the interview, observation and documentation methods. Focused data analysis using the Miles \& Huberman model, namely data reduction, presentation and conclusion drawing. The findings of this study indicate that there are three roles of the principal in developing the quality of education at SD Negeri 001 Bonai Darussalam, namely the principal as a manager, educator and motivator. The supporting factors in developing the quality of education at SD Negeri 001 Bonai Darussalam are good human resources (HR), the existence of a teacher's jihad spirit in teaching and educating good students to make outstanding students, and the cohesiveness of school residents.
\end{abstract}

Keywords: the role of the principal, developing the quality of education

Abstrak: Penelitian ini bertujuan untuk mendeskripsikan peran kepala sekolah dalam mengembangkan mutu pendidikan, faktor pendukung dalam mengembangkan mutu pendidikan, dan faktor penghambat dalam mengembangkan mutu pendidikan di SD Negeri 001 Bonai Darussalam. Penelitian ini menggunakan pendekatan kualitatif bersifat deskriptif. Sumber data penelitian adalah kepala sekolah dan dua guru. Teknik pengumpulan data menggunakan metode wawancara, observasi, dan dokumentasi. Analisis data menggunakan model Miles \& Huberman yang meliputi reduksi data, penyajian, dan penarikan kesimpulan. Temuan penelitian menunjukan bahwa terdapat tiga peran kepala sekolah dalam mengembangkan mutu pendidikan di SD Negeri 001 Bonai Darussalam, yaitu kepala sekolah sebagai manager, educator, dan motivator. Adapun faktor pendukung dalam mengembangkan mutu pendidikan di SD Negeri 001 Bonai Darussalam yaitu sumber daya manusia (SDM) yang baik, adanya semangat jihad guru dalam mengajar dan mendidik yang baik untuk menjadikan siswa berprestasi, dan kekompakan warga sekolah. Sedangkan faktor penghabatnya adalah kurangnya sarana prasarana, kompetensi guru yang masih kurang, dan faktor lingkungan.

Kata kunci: peran kepala sekolah, mengembangkan mutu pendidikan 


\section{PENDAHULUAN}

Pembelajaran ialah kebutuhan manusia yang sangat berarti dalam kehidupan manusia itu sendiri. Manusia pada hakikatnya tidak hanya bergantung pada alam tanpa pengaruh lain. Dalam proses tersebut timbul pengaruh yang hendak didapat oleh manusia lain yang membawa pergantian perilaku atas manusia yang dipengaruhinya. Undang-Undang Dasar Negeri Republik Indonesia 1945 pasal 31 ayat 1 serta 2 menegaskan bahwa setiap masyarakat negeri berhak memperoleh pendidikkan, serta tiap masyarakat negeri harus menjajaki pembelajaran dasar serta pemerintah harus membiayainya.

Peran atau peranan dapat diartikan sebagai perilaku yang diatur dan diharapkan dari seseorang dalam posisi tertentu. Peranan/role merupakan konsep yang tidak dapat dipisahkan dari status atau kedudukan dan posisi seseorang. Antara peranan dan status ibarat mata uang yang sama, oleh karena itu tidak dapat mengerti status tanpa peranan, begitu sebaliknya (Rosyadi, 2015) .

Dalam dunia pendidikan, kepala sekolah menjadi ujung tombak dalam proses pembelajaran yang berlangsung di sekolah. Kepala sekolah sangat berperan penting dalam suksesnya pembelajaran di sekolah. Kedudukan kepemimpinan kepala sekolah yang sudah diimplementasikan diharapkan mampu menciptakan pembelajaran bermutu, karena pembelajaran bermutu ialah kunci dalam membangun manusia yang kompeten serta beradab. Dalam hal ini mampu menciptakan lulusan yang cocok dengan harapan publik, baik dalam mutu individu, moral, pengetahuan, ataupun kompetensi kerja yang menjadi ketentuan absolut dalam kehidupan warga. Dalam merealisasikan pembelajaran bermutu, dituntut pelaksanaan program kualitas yang terfokus pada upaya-upaya penyempurnaan kualitas segala komponen serta aktivitas pembelajaran di sekolah dasar.

D.E. Mc Farland mengemukakan bahwa kepemimpinan adalah suatu proses di mana pimpinan dilukiskan akan memberi perintah atau pengaruh, bimbingan atau proses mempengaruhi pekerjaan orang lain dalam memilih dan mencapai tujuan yang telah ditetapkan (Danim, 2010). Kepemimpinan hanya dapat dilakukan oleh seorang pemimpin. Seorang pemimpin adalah seseorang yang memiliki keterampilan kepemimpinan yang dapat mempengaruhi posisi atau pendapat seorang orang tanpa bertanya alasannya (Bahrum \& Sinaga, 2015).

Kepala sekolah merupakan pemimpin pendidikan tingkat satuan pendidikan yang harus memiliki dasar kepemimpinan yang kuat (Mulyasa, 2017). Wiyono (dalam Gaol, 2017) meyatakan bahwa kepemimpinan kepala sekolah merupakan salah satu aspek yang menentukan keberhasilan pendidikan di sekolah. Kepala sekolah adalah jabatan pemimpin yang tidak bisa diisi oleh orangorang yang didasarkan atas pertimbangan-pertimbangan (Wahjosumidjo, 2011). 
Nai \& Wijayanti menyatakan bahwasa fungsi kepala sekolah sebagai diantarannya, 1) membantu terciptanya kondisi dan suasana kerja sama dengan penuh rasa kebebasan, 2) pemimpin membantu kelompok untuk mengorganisir diri yaitu ikut serta dalam memberikan rangsangan dan bantuan kepada kelompok dalam menetapkan dan menjelaskan tujuan, 3) pemimpin membantu kelompok dalam menganalisis situasi untuk kemudian menetapkan prosedur mana yang paling praktis dan efektif, pemimpin bertanggung jawab dalam mengambil keputusan, 4) pemimpin memberi kesempatan kepada kelompok untuk belajar dari pengalaman, 5) pemimpin bertanggung jawab dalam mengembangkan dan mempertahankan eksistensi organisasi (Nai \& Wijayanti, 2018).

Kepala sekolah sangat berperan dalam meningkatkan mutu pendidikan di sekolah. Kepala sekolah juga harus paham tentang pembelajaran, mulai dari merencanakan, melaksanakan, sampai pada evaluasi sebagai bahan pembinaan guru dalam meningkatkan kinerjanya (Suhardiman, 2012). Jadi, kepala sekolah tidak hanya paham cara mengelola sekolah sesuai dengan perannya sebagai menajer, tetapi harus paham tentang berbagai hal yang berkaitan dengan pembelajaran.

Berdasarkan hasil wawancara dengan kepala sekolah SD Negeri 001 Bonai Darussalam Kabupaten Rokan Hulu pada tanggal 4 Januari 2021 diperoleh hasil bahwa mutu pendidikan di SD Negeri 001 Bonai Darussalam sudah berupaya. Namun masih ada beberapa masalah yang dihadapi oleh kepala sekolah dalam meningkatkan mutu pendidikan, diantarannya (1) kurangnya keberanian kepala sekolah untuk mengajukan perbaikan sarana dan prasarana yang menunjang lancarnya proses kegiatan belajar mengajar, (2) lingkungan masyarakat yang menjadi faktor penghambat meningkatnya mutu pendidikan di SD Negeri 001 Bonai Darussalam, dan (3) kompetensi guru yang kurang mendukung dalam meningkatkan mutu pendidikan di SD Negeri 001 Bonai Darussalam.

Oleh karena hal tersebut mutu pendidikan belum mencapai hasil yang maksimal. Hal ini sejalan dengan penelitian (Rosyadi, 2015) yang membahas tentang peran kepala sekolah sebagai manajer dalam meningkatkan mutu pendidikan di SMP 1 Cilawu Garut. Dari penelitian tersebut dapat dilihat permasalahan dalam meningkatkan mutu pendidikan di SMP 1 Cilawu Garut, yaitu kepala sekolah terkadang kurang berperan aktif, sarana dan prasarana juga dihadapi oleh sekolah sehingga dalam proses belajar mengajar kurang maksimal, adanya pendidik dan tenaga kependidikan yang kurang disiplin kerja, dan koordinasi antara kepala sekolah dengan pendidik dan tenaga kependidikan terkadang terjadi perbedaan pendapat sehingga menimbulkan sebuah ketidaknyamanan dalam menjalankan tugas. Sehingga mutu pendidikan hendaknya mampu menghasilkan lulusan yang terampil, mampu sesuai dengan tingkat pendidikannya, jujur, dan memiliki moral yang baik. Peningkatan mutu pendidikan yang lebih berkualitas antara lain melalui pengembangan dan 
perbaikan kurikulum dan sistem evaluasi, perbaikan sarana pendidikan, pengembangan dan pengadaan materi ajar, serta pelatihan bagi guru dan tenaga kependidikan lainnya.

Maka dari itu kepala sekolah sebagai pemimpin harus jeli dalam membaca peluang dan ancaman yang akan datang. Apabila kepala sekolah tidak memperhatikan penentuan keberhasilan maupun kualitas pendidikan disebuah sekolah, maka sekolah tersebut akan sulit untuk mencapai mutu pendidikan yang berkualitas.

\section{METODE}

Metode yang digunakan pada penelitian ini adalah deskriptif dengan pendekatan kualitatif. Penelitian kualitatif merupakan metode penelitian yang berlandaskan pada filsafat postpositivisme, digunakan untuk meneliti pada kondisi obyek yang alamiah (Sugiyono, 2015). Penelitian ini mendeskripsikan peran kepala sekolah dalam mengembangkan mutu pendidikan, faktor pendukung kepala sekolah dalam mengembangkan mutu pendidikan, dan faktor penghambat kepala sekolah dalam mengembangkan mutu pendidikan.

Lokasi penelitian dilakukan di SD Negeri 001 Bonai Darussalam Kabupaten Rokan Hulu yang beralamat Jl. Syekh Muhammad Kayo, Sontang, Kecamatan Bonai Darussalam, Kabupaten Rokan Hulu. Sumber data penelitian ini adalah kepala sekolah dan guru. Tidak ada batas pengambilan sumber data pada penelitian ini.

Teknik pengumpulan data dalam penelitian ini adalah wawancara, observasi, dan dokumentasi. Instrumen dalam penelitian adalah penelitian itu sendiri (Sugiyono, 2014) Analisis data hasil penelitian menggunakan model Miles dan Huberman, yaitu meliputi proses reduksi data (data reduction), penyajian data (data display), dan penarikan kesimpulan (conclusion drawing) (Gunawan, 2013).

\section{HASIL DAN PEMBAHASAN}

Kepala sekolah dalam menjalankan peran kepemimpinannya dapat diwujudkan dengan mengaplikasikan program-program yang telah direncanakan dan disusun oleh kepala sekolah. Dalam mengaplikasikan program tersebut, kepala sekolah harus bekerja secara maksimal agar perannya sebagai seorang pemimpin dapat terlaksana dengan baik. Dengan demikian mutu pendidikan di sekolah yang dipimpin dapat mangalami kemajuan sesuai dengan standar mutu pendidikan nasional. Adapun program-program kerja yang dibuat oleh kepala sekolah diantaranya, meningkatkan pemahaman dan penguasaan guru terhadap kurikulum 2013, meningkatkan keterampilan guru, dan melengkapi buku-buku sumber pelajaran baik untuk pegangan guru maupun untuk pegangan siswa. 
Kepemimpinan kepala sekolah SD Negeri 001 Bonai Darussalam tergolong kepada tipe kepemimpinan demokratis di mana kepala sekolah selalu mengadakan musyawarah dengan seluruh dewan guru, staf, dan tata usaha dalam menetapkan setiap keputusan yang akan diambil. Kepemimpinan kepala sekolah cukup bijaksana dan bertanggung jawab yang diwujudkan dalam mengambil keputusan kemudian menyelesaikan sebuah masalah dan bertanggung jawab dalam kepemimpinannya. Kepala sekolah telah menjalankan peran kepemimpinanya secara baik. Hal tersebut tercermin dari iklim kerja sekolah yang menyenangkan. Kepala sekolah tidak memberikan batasan atau perbedaan antara kepala sekolah dengan seluruh dewan guru, staf, dan tata usaha. Mereka semua berbaur menjadi satu kesatuan.

Peran kepala sekolah dalam mengembangkan mutu pendidikan di SD Negeri 001 Bonai Darussalam yaitu dengan mengaplikasikan program yang telah direncanakan dan disusun oleh kepala sekolah. Peran kepemimpinan yang dijalankan kepala sekolah untuk mengembangkan mutu pendidikan di SD Negeri 001 Bonai Darussalam, yaitu sebagai manager, educator, dan motivator. Permadi (dalam Mulyasa, 2017) berpendapat bahwa kepala sekolah dituntut untuk mampu memimpin, mengorganisir, dan mengelola pelaksanaan program belajar mengajar yang diselenggarakan di sekolah yang ia pimpin. Dalam hal ini, kepala sekolah harus menjadi supervisor tim yang terdiri dari guru, staf, dan siswa dalam mewujudkan proses belajar mengajar yang efektif dan efesien sehingga tercapai produktivitas belajar yang dapat meningkatkan mutu pendidikan.

Berkaitan dengan peran kepala sekolah dalam peningkatan kualitas pendidikan tidak terlepas dari perilaku pemimpin yang diciptakan yaitu paternalistic, kebutuhan-kebutuhan semu, kemandirian dalam bekerja lemah, konsensus, dan menghindar. Perilaku paternalistic dalam kepemimpinan memunculkan sikap bawahan. Keengganan bawahan untuk mengungkapkan pikiran, pendapat, dan kritik terhadap atasan karena khawatir dianggap menentang atasan, dominasi atasan terhadap bawahan sangat kuat, sehingga bila muncul gagasan pembaharuan dari bawahan seringkali dianggap sebagai tantangan terhadap kebijakan pemimpin (Mulyasa, 2017).

Perilaku kepatuhan semu dalam pemimpin merupakan pengaruh paternalistic. Selama seseorang masih menduduki posisi pimpinan, maka loyalitas dan rasa hormat terhadap pribadi pimpinan tinggi. Perilaku kemandirian kurang, karena telah terkondisi kebiasaan menunggu perintah atasan (pengarahan) sehingga inisiatif, kreatif, dan tanggung jawab kurang bagi bawahan. Perilaku consensus merupakan produk musyawara atas dasar gotong-royong. Perilaku menghindari sering juga disebut dengan tidak konsekuen menghadapi kenyataan. Perilaku menghindar tersebut menghasilkan sikap yang tidak siring antara kata dengan perbuatan. 
Gaya kepemimpinan kepala sekolah merupakan harapan yang tinggi bagi peningkatan kualitas pendidikan, karena keberhasilan kepemimpinan di sekolah akan mempunyai pengaruh secara langsung terhadap hasil belajar siswa (Mulyasa, 2017). Sehubungan dengan itu, kepala sekolah harus mampu melaksanakan peran dan fungsi supervisor kepada guru untuk mengambangkan profesi. Dalam kaitannya dengan peningkatkan kualitas pendidikan, kepala sekolah tidak hanya bertindak sebagai menager yang mengatur segala sesuatu tentang proses belajar mengajar, namun juga harus tampil sebagai pemimpin pengajaran yang bertugas mengawasi jalannya kegiatan belajar mengajar di sekolah yang dipimpinnya. Fungsi pengawasan tersebut harus dilakukan secara melekat, baik terhadap perencana pengajaran, pelaksanaan, maupun terhadap penilaian atau evaluasi proses nelajar mengajar yang dilakukan guru.

Kesolidan antar warga sekolah ikut menjadi salah satu faktor penunjang. Adanya motivasi guru terhadap siswa untuk menjadikan siswanya maju dan berprestasi, guru di SD Negeri 001 Bonai Darussalam senantiasa selalu mengayomi dan mendorong dalam kegiatan pengembangan kualitas diri. Adapun faktor pendukung lainnya sumber adalah daya manusia (SDM) yang baik, adanya semangat jihad guru dalam mengajar dan mendidik yang baik untuk menjadikan siswa berprestasi.

Guru menjadi peran sental dalam proses pembelajaran di SD Negeri 001 Bonai Darussalam sehingga guru dituntut mampu menanamkan nilai kognitif, afektif, dan psikomotorik agar peserta didik berkembang sesuai dengan apa yang diharapkan. Dengan demikian dapat melahirkan generasi muda yang berkualitas.

Faktor pendukung kepala sekolah dalam meningkatkan mutu pendidikan dibagi dua, yaitu faktor internal dan eksternal. Faktor internal pada sekolah yaitu kepemimpinan kepala sekolah, dukungan yayasan, dan sarana prasarana. Kemudian faktor eksternal sekolah yaitu kebutuhan masyarakat akan pendidikan dan persaingan antar sekolah (Zahro, dkk, 2018).

Pendapat lain menyatakan bahwa faktor pendukung kepala sekolah dalam meningkatkan mutu pendidikan adalah sebagai berikut.

1. Kemajuan teknologi yang mempermudah untuk komunikasi.

2. Partisipasi orang tua siswa.

3. Kemauan dan kemampuan yang ada dalam diri siswa untuk mengikuti program kepala sekolah.

4. Sekolah yang memiliki modah kepercayaan.

5. Fasilitas yang diberikan oleh sekolah (Kinanti, 2016) 
Berdasarkan hasil penelitian yang telah peneliti lakukan melalui teknik pengumpulan data wawancara, obsevasi, dan dokumentasi tetang faktor penghambat kepala sekolah dalam mengembangkan mutu pendidikan di SD Negeri 001 Bonai Darussalam meliputi beberapa hal.

Kesadaran warga sekolah yang kurang dalam hal pembelajaran ataupun memanfaatkan fasilitas yang ada. Adapun faktor penghambat lainnya yaitu kurangnya sarana prasarana yang di SD Negeri 001 Bonai Darussalam. Selain itu masyrakat yang ada di sekeliling sekolah memiliki pemikiran yang kuno terhadap mutu pendidikan. Kompetensi guru yang masih kurang dalam mengembangkan mutu pendidikan yang ada di SD Negeri 001 Bonai Darussalam juga menjadi bagian dalam faktor penghambat kepala sekolah dalam mengembangkan mutu.

Aspek penghambat lainnya yakni benturan sistem keadministrasian dengan dinas. Sepanjang ini kepala sekolah membimbing guru guna tidak berpacu pada sistem keadministrasian dinas yang susah serupa format piranti, silabus, serta sebagainya. Kepala sekolah menginginkan agar guru lebih fokus untuk mengajar, bukan fokus pada perangkat dinas. Benturan ini berlangsung sebab kemauan dinas kurang cocok dengan visi misi sekolah, seperti jumlah jam pelajaran dan banyaknya guru mata pelajaran. Rendahnya keahlian guru juga disebabkan karna mereka belum mampu mempraktekkan digital learning secara baik, sehingga guru kurang inovatif. Terdapat guru yang rendah kesadarannya pada peningkatan kualitas, sehingga masih terdapat guru yang kurang berkompeten.

Banyak faktor penghambat tercapainya kualitas kepemimpinan seorang kepala sekolah seperti proses pengangkatannya tidak transparan, rendahnya mental kepala sekolah yang ditandai dengan kurangnya motivasi, kurangnya disiplin dalam melakukan tugas, seringnya datang terlambat, wawasan kepala sekolah yang masih sempit, serta banyak faktor lain yang menghambat kinerja seorang kepala sekolah untuk meningkatkan kualitas pendidikan pada lembaga yang dipimpinnya. Salah satu kendala dalam meningkatkan mutu pendidikan adalah kepala sekolah yang kurang tepat waktu dalam melaksanakan program peningkatan mutu Fitrah, 2017).

\section{KESIMPULAN}

Berdasarkan penelitian dan pembahasan yang telah dilakukan peneliti terhadap analisis peran kepala sekolah dalam mengembangkan mutu pendidikan di SD Negeri 001 Bonai Darussalam Kabupaten Rokan Hulu dapat disimpulkan sebagai berikut.

1. Kepemimpinan sebagai kegiatan untuk mempengaruhi orang-orang yang diarahkan terhadap pencapaian tujuan organisasi. Hasil penelitian ini menunjukan bahwa tipe kepemimpinan demokratis yang dijalankan kepala sekolah di SD Negeri 001 Bonai Darussalam berpengaruh terhadap sistem kerja yang menyenangkan antara kepala sekolah dengan seluruh warga sekolah. 
Hal ini mengandung implikasi agar kedepannya kepala sekolah dapat mempertahankan kepemimpinan demokratis yang dijalankannya agar senantiasa terjalin keharmonisan antara seluruh warga sekolah.

2. Peran kepemimpinan yang dijalankan kepala sekolah di SD Negeri 001 Bonai Darussalam sebagai manager, educator, dan motivator berpengaruh terhadap upaya mengembangkan mutu pendidikan di SD Negeri 001 Bonai Darussalam. Hal ini mengandung implikasi agar kedepannya peran kepemimpinan yang dijalankan kepala sekolah sebagai manager, educator dan motivator dapat terlaksana agar mutu pendidikan di sekolah dapat sesuai dengan tujuan yang diharapkan.

3. Faktor pendukung dalam mengembangkan mutu pendidikan di SD Negeri 001 Bonai Darussalam yaitu kesolidan antar warga sekolah, adanya motivasi guru terhadap siswa untuk menjadikan siswanya maju dan berprestasi, guru di SD Negeri 001 Bonai Darussalam senantiasa selalu mengayomi dan mendorong dalam kegiatan pengembangan kualitas diri. Adapun faktor pendukung lainnya meliputi sumber daya manusia (SDM) yang baik, adanya semangat jihad guru dalam mengajar dan mendidik yang baik untuk menjadikan siswa berprestasi, dan kekompakan warga sekolah. Segala bentuk motivasi tersebut berpengaruh dalam keberhasilan belajar siswa.

4. Faktor penghambat dalam mengembangkan mutu pendidikan di SD Negeri 001 Bonai Darussalam faktor yang masih secara umum dihadapi oleh beberapa sekolah di pedesaan dalam proses mengembangkan mutu pendidikan.

\section{DAFTAR PUSTAKA}

Bahrum, Syazhashah Putra \& Sinaga, Inggrid Wahyuni. (2015). Pengaruh Kepemimpinan dan Motivasi Kerja Terhadap Kinerja Pegawai (Studi Pada Pegawai Lembaga Dewan Kawasan Perdagangan Bebas Pelabuhan Bebas Batam Bintan Karimun). Jurnal Akuntansi, Ekonomi dan Manajemen Bisnis, 3(2).

Denim, Sudarwan. (2010). Kepemimpinan Pendidikan. Bandung: Alfabeta.

Fitrah, Muh. (2017). Peran Kepala Sekolah Dalam Meningkatkan Mutu Pendidikan. Jurnal Penjaminan Mutu, 3(1).

Gaol, Nasib Tua Lumban. (2017). Teori dan Implementasi Gaya Kepemimpinan Kepala Sekolah. Jurnal Manajemen Pendidikan, 4(2).

Gunawan, I. (2013). KUALITATIF Imam Gunawan. Pendidikan, 143. http://fip.um.ac.id/wpcontent/uploads/2015/12/3_Metpen-Kualitatif.pdf 
Kinanti, Yunida Cahya. (2016). Kemitraan Sekolah Dalam Meningkatkan Mutu Pendidikan Di Sma Negeri2 Yogyakarta. Jurnal Filsafat dan Sosiologi Pendidikan, 5(5).

Mulyasa, E. (2017). Manajemen \& Kepemimpinan Kepala Sekolah. Jakarta: Bumi Aksara.

Nai, Hendrikus \& Wijayanti, Wiwik. (2018). Pelaksanaan Tugas dan Fungsi Kepala Sekolah Pendidikan Menengah Negeri. Jurnal Akuntabilitas Manajemen Pendidikan, 6(2).

Rosyadi, Irfan Yogi \& Pardjono. (2015). Peran Kepala Sekolah Sebagai Manajerdalam Meningkatkan Mutu Pendidikan Di Smp 1 Cilawu Garut. Jurnal Akuntabilitas Manajemen Pendidikan, 3(1).

Sugiyono. (2014). Metode Penelitian Pendidikan Pendekatan Kuantitatif, Kualitatif, dan R\&D. alfabeta.

Sugiyono. (2015). Metode Penelitian Kuantitatif, Kualitatif dan R\&D. Bandung: Alfabeta.

Suhardiman, Budi. (2012). Studi Pengembangan Kepala Sekolah Konsep dan Aplikasi. Jakarta: Rineka Cipta.

Undang-Undang Dasar Negara Republik Indonesia Tahun 1945.

Wahjosumidjo. (2011). Kepemimpinan Kepala Sekolah. Jakarta: PT Raja Grafindo Persada.

Zahro, Mar'atuz Anna, dkk. (2018). Kepemimpinan Perubahan Kepala Sekolah Dalam Peningkatan Mutu Pendidikan. Jurnal Administrasi dan Manajemen Pendidikan, 1(3). 
ANALISIS PERAN KEPALA SEKOLAH DALAM MENGEMBANGKAN MUTU PENDIDIKAN...

Lulu Lestari, Elpri Darta Putra 